\title{
Mineração
}

\section{Fluxo de material fragmentado em passagem de minério nas minas subterrâneas: a prática corrente}

\author{
José Margarida da Silva \\ Eng. de Minas, Dr. EEUFMG, Professor Adjunto da Escola de Minas/UFOP \\ E-mail:jms@demin.ufop.br \\ Maria de Fátima Andrade Gripp \\ Eng. de Minas, Dr. Ing. ENSMP, Professor Adjunto da Escola de Engenharia/UFMG \\ E-mail:mgripp@demin.ufmg.br
}

\section{Resumo}

Esse trabalho é parte de pesquisa realizada para preparação de tese de doutorado e apresenta estudo do fluxo por gravidade de material fragmentado em mineração subterrânea. É descrita a prática corrente em minas brasileiras e estrangeiras, enfocando os índices de acidentes, as ações preventivas e corretivas nas operações que utilizam o fluxo por gravidade de minério desmontado em passagens, presentes em diversos métodos de lavra, como na lavra por subníveis, por corte e enchimento e nos métodos que utilizam o abatimento controlado do teto da escavação subterrânea.

Palavras-chave: material fragmentado, passagem de minério, mineração subterrânea, fluxo por gravidade, estocagem.

\begin{abstract}
This article shows some results of a doctorate thesis about the gravity flow of bulk material in an underground mine. It describes the practices in Brazilian mines and in other countries, focusing on accident data, preventive and corrective actions, in mining operations that use gravity flow to transport fragmented material from the excavation of ore passes in several mining operations, such as in underground mining using cut and fill methods and caving methods.
\end{abstract}

Keywords: bulk material, ore pass, underground mining, gravity flow, storage. 


\section{Introdução}

Material granular é um conjunto de partículas sólidas distintas, que interagem apenas nos pontos de contato. $\mathrm{O}$ tamanho, a forma e a orientação das partículas variam. O material granular pode se comportar, às vezes, como um sólido, como um líquido, como um gás e, ainda, de uma maneira peculiarmente sua.

Os princípios do fluxo por gravidade de materiais fragmentados foram formulados nos anos 60, do século XX. Mas, face às questões ainda sem resposta, existe uma preocupação mundial com o comportamento mecânico do material granular, levando à realização de estudos apoiados por empresas e por órgãos governamentais.

Em diversas situações, o material granular produzido por processo de fragmentação é denominado material fragmentado. O fluxo por gravidade desse material é um processo de transporte importante em diversas indústrias, envolvendo, na mineração, as operações de carregamento, estocagem e transporte, sendo comum o fluxo por gravidade em passagens, silos, britadores, alimentadores de equipamentos e chutes de descarga.

Janelid e Kvapil (1966) desenvolveram abordagens voltadas para o fluxo de matérias fragmentados em escavações subterrâneas, quando planejaram a Mina de Kiruna, na Suécia. Entre as questões importantes desse fluxo, estão a segurança dos trabalhos e os custos resultantes de paradas e de operações de desbloqueios do material retido. Os índices apontam que a maioria dos acidentes em minas subterrâneas está ligada a operações em passagens (Beus et alii, 1997). O transporte de materiais representa um custo dos mais elevados na operação de uma mina.Em alguns casos, ultrapassam metade do custo de lavra.

Na mineração subterrânea, o transporte de material fragmentado é necessário a partir da frente de lavra. O principal fator a ser observado, para o fluxo de material grosseiro (de dimensão superior a $20 \mathrm{~cm}$ ), é a relação entre a natureza do material e a inclinação de transporte. Até $40^{\circ}$ de inclinação da escavação, os materiais fragmentados são transportados por caminhões, carregadeiras, vagões e correias transportadoras. A partir de $40^{\circ}$, ocorre o fluxo por gravidade em escavações, em passagens e através de esquipes (skips).

Passagens são escavações inclinadas ou verticais, escavadas na rocha ou construídas à medida do avanço da lavra. Têm seções quadradas, retangulares ou circulares, de dimensão característica da ordem de 1 a 9m, comprimento de 18 a $180 \mathrm{~m}$, espaçamento de 5 a $15 \mathrm{~m}$, dependendo do método de lavra aplicado (Beus et alii, 2001). Observa-se que alguns autores, como Kvapil (1965), denominam de chute a passagem que apresenta dispositivo de controle do fluxo, enquanto outros autores reservam a denominação de chute especificamente para o dispositivo de controle de descarga, sendo, às vezes, denominado, ainda, bica de descarga.

As passagens constituem a forma primária de transferência vertical de minério ou estéril extraído para silos e pontos de carregamento. O silo é empregado para prover capacidade de regularização do fluxo do minério. O material fragmentado é, normalmente, retirado do silo por um chute. As passagens são, também, usadas para estocagem temporária de minério. Dos silos e pontos de carregamento, o material fragmentado é transportado até a superfície.

O fluxo por gravidade de material fragmentado é muito empregado em diversas minas subterrâneas. Em levantamento, abrangendo variados métodos de lavra, minas, tipos de minério e profundidades, conclui-se que cerca de 60\% das minas usam passagens ou silos (Germani, 2002; De la Vergne, 2000; Pfleider et al., 1968).

Nem todo material fragmentado é adequado para o transporte por passagens com chutes. Conforme Kvapil (1965), o material adequado é composto de fragmentos menores que $20 \mathrm{~cm}$ e pela ausência de finos e de constituintes terrosos, de modo que a aglomeração seja evitada. A distinção entre partículas finas e grosseiras é algo arbitrário. Para Beus et alii (2001), finos são partículas de tamanho inferior a 0,072mm (malha 200 Tyler).

No sistema de fluxo por gravidade, três versões são possíveis no realce, em função da granulometria do material fragmentado: para material bem fragmentado, de fluxo livre, a utilização da força da gravidade e ramificações das passagens (fingers), para transferência do material, com controle da granulometria no subnível de grelha; para material com menor grau de fragmentação, a utilização de rastelo (scraper), para levar o material aos pontos de carregamento na galeria de transporte; para material mais grosseiro, a utilização de carregadeira de descarga traseira, carregadeira rebaixada LHD, entre outros, para conduzir o material aos transportadores (Hartman, 1987).

Os seguintes problemas podem afetar o desempenho em passagens de minério, segundo Hambley (1987):

1. Entupimentos (blockages) devido a arcos coesivos.

2. Bloqueios (hang-ups) devido a arcos mecânicos.

3. Suspensão de fluxo, quando o material forma um canal de fluxo vertical estável (pipe ou rathole) no interior da passagem.

4. Desgaste do revestimento e/ou desplacamento das paredes da passagem.

Como exemplo, pode ser citado o caso da Mina Urad, USA, lavra de molibdênio, em que um arco de material fragmentado formado, com área de 90m x $135 \mathrm{~m}$, rompeu-se após nove meses, causando dano extenso (Hartman, 1987).

\section{A prática na mineração subterrânea}

Na mineração subterrânea, no que diz respeito ao fluxo de material fragmentado, a literatura disponível é muito diversificada, não existindo uma linguagem uniformizada, de aceitação geral, nem padronização de parâmetros e, conse- 
qüentemente, não há estatísticas disponíveis, nem sistematização dos trabalhos já realizados.

A prática corrente mostra algumas ações preventivas. É comum a limitação na faixa granulométrica admissível no desmonte por explosivos, relativamente à quantidade de finos produzida. Para minimizar os finos, antes que sejam descarregados na passagem, podem ser usados equipamentos de graduação. Também é comum o uso de rompedores e/ou de britadores, antes das passagens, para reduzir o tamanho de fragmentos de minério que sejam muito grandes para passar através de grelhas para os pontos de carregamento.

O primeiro problema na eliminação de um bloqueio é sua localização. Isso pode ser facilitado, se há como visualizar o entupimento através de um local de acesso (Figura 1). Como a largura do chute é, geralmente, menor que a abertura de alimentação da passagem, a probabilidade de ocorrência de bloqueios próximos a essa região é maior. Beus et alii (2001) citam a inspeção visual, a utilização de sensores ou de câmera introduzida a partir da entrada da passagem como técnicas alternativas para delinear o nível de material e os vazios.

Entre as ações corretivas, o método usual de destruir um bloqueio é inserir explosivo na passagem através de um furo, realizado com essa finalidade, acima do portão. Então o explosivo é iniciado e o bloqueio é destruído. O minério acima do bloqueio cai e se choca com o portão. Curvas e joelhos são, às vezes, usadas na base de passagens para permitir proteção contra o impacto sobre o portão e para controle do fluxo.

Algumas vezes, dado o dano sofrido, as passagens precisam ser abandonadas. Não existem dados disponíveis da vida útil dessas escavações, que têm vida útil projetada em função do método de lavra aplicado, mas não se registra o tempo de sua utilização efetiva.

Diversas recomendações práticas são listadas na literatura, com respeito a dimensões, à inclinação e ao espaçamen- to das passagens, à granulometria do material e à presença de finos. O domínio de fluxo livre é, geralmente, limitado pela linha que representa uma escavação da ordem de 4 a 6 vezes o tamanho máximo de partícula em fluxo (Figura 2).

A finalidade dos ensaios em laboratório realizados por Beus et alii (1997) foi avaliar a resposta de uma estrutura típica de chute a dadas condições de carregamento e, portanto, a forças sobre o portão de controle de descarga. Foi construído, em escala real, um modelo típico de chute e de estrutura de suporte (Figura 3). A estrutura real do portão é suspensa sobre vigas de aço, ligadas a parafusos. Os ensaios consistiram em aplicação de carga através de uma placa de distribuição, com área próxima do valor da área da seção transversal do portão real. As cargas estáticas e dinâmicas foram medidas em laboratório, usandose uma simulação em escala reduzida de uma passagem. Os ensaios de campo se iniciaram em passagens na mina para se determinarem as cargas estáticas e dinâ- micas. Os dados dos ensaios seriam comparados com os dados de mina para caracterizar o comportamento real.

Nos eventos científicos no Brasil, tem-se verificado uma preocupação com esse tema, com trabalhos de pesquisa a respeito de alternativas de enchimento em minas subterrâneas e de monitoramento de cavidades em que acontece o abatimento de material.

\section{Conclusões}

O escoamento de sistemas granulares confinados mostra-se bastante complexo e dependente de inúmeros parâmetros, sejam relativos ao material sejam ao silo ou à escavação.

Não estão disponíveis dados quantitativos ou qualitativos acessíveis aos mineradores a respeito do fluxo por gravidade em passagens de minério. Os relatos do cotidiano de operadores e supervisores são esparsos e não constituem documentação sistematizada para

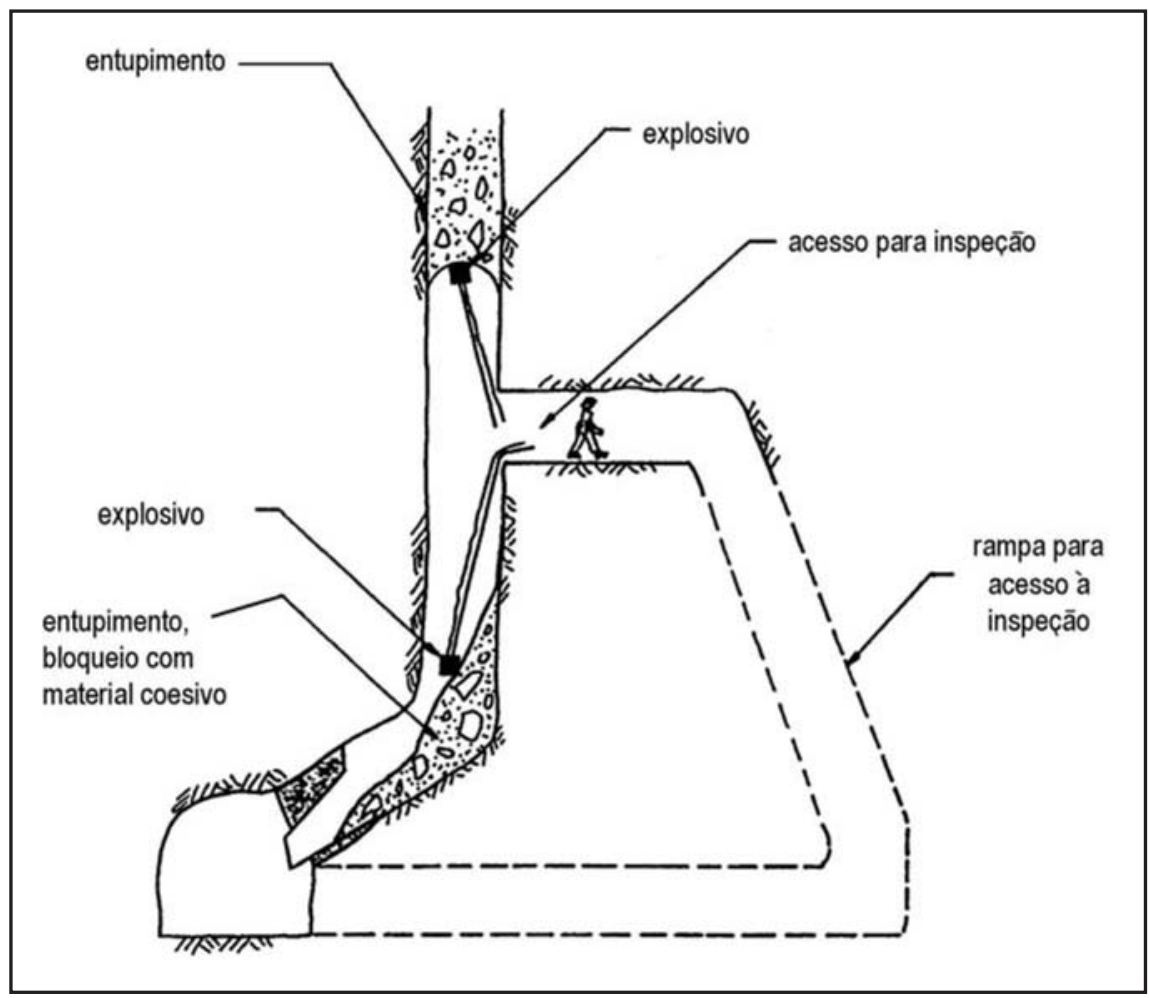

Figura 1 - Formas usuais de desobstrução de entupimentos nas passagens (Stacey \& Swart, 1997). 
extração de informações ou de interpretações consistentes que auxiliem no projeto e na execução do fluxo por gravidade em passagens de minério. $O$ primeiro passo para a melhoria seria a construção de metodologia de documentação criteriosa de fenômenos de fluxo em passagens.

A prática corrente, no fluxo por gravidade de material fragmentado, em mineração subterrânea, mostra algumas ações preventivas e outras corretivas. A pesquisa deve conduzir a mudanças de diretrizes para projeto de passagens e sistemas similares de estocagem e de transporte de material nas minas e a melhoria significativa da segurança.

A grande utilização do fluxo por gravidade, o custo com paradas, as questões de segurança, a abertura de novas minas subterrâneas e o aprofundamento de minas já existentes reforçam a necessidade de estudos nessa área.

\section{Agradecimentos}

Os autores expressam seus agradecimentos à CAPES e à FAPEMIG, que financiaram os estudos e ao graduando Solanno Fabrícius C. Dias (DEMIN/EM/ UFOP), pela auxílio na realização de pesquisa bibliográfica e de campo.

\section{Referências Bibliográficas}

BEUS, M. J., PARISEAU, W. G., STEWART, M., IVERSON, S. Design of ore passes. In: HUSTRULID, W., BULLOCK, R. (eds). Underground Mining Methods: Engineering Fundamentals and International Case Studies, Littleton, CO. Society of Mining, Metallurgy and Exploration, p. 627-634. 2001.

BEUS, M. J., IVERSON, S., STEWART, B. Application of physical modeling and particle flow analysis to evaluate orepass design. In: Transactions of Institute of Mining and Metallurgy, 106, p. A110-A117. 1997.

GERMANI, D. J. A mineração no Brasil. Relatório ao Programa das Nações Unidas para o Desenvolvimento, Ministério da Ciência e Tecnologia, 2002. 59 p.

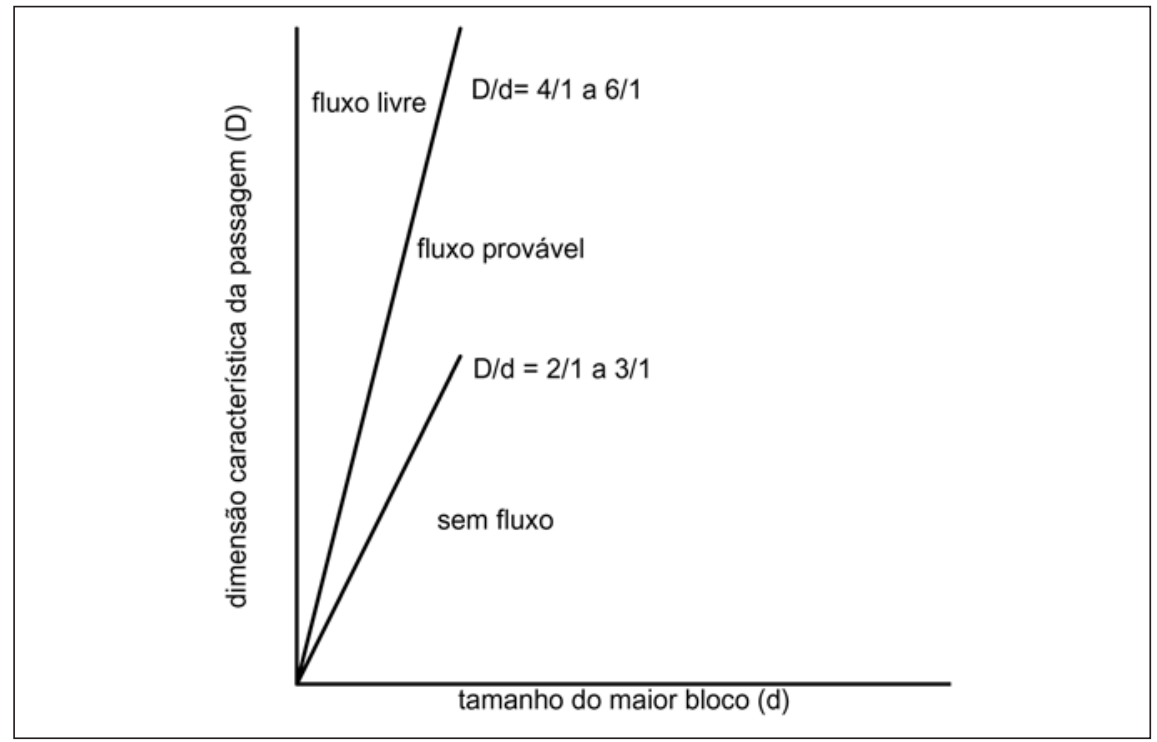

Figura 2 - Relações dimensionais entre a dimensão característica da seção da passagem e a granulometria do material.

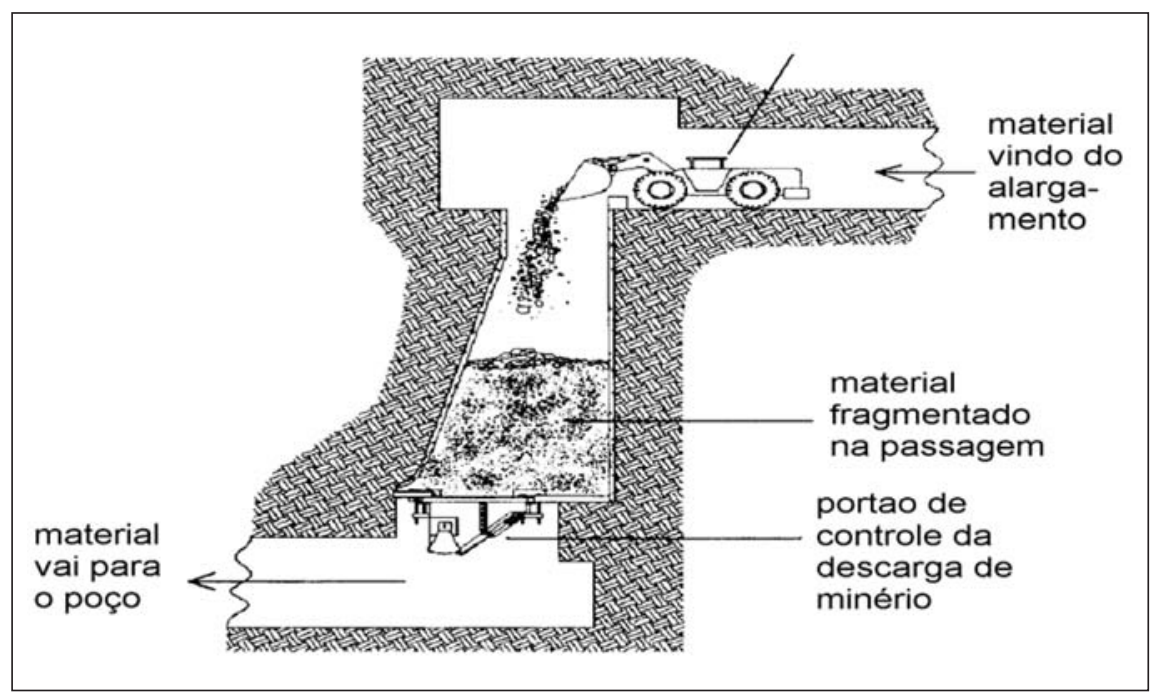

Figura 3 - Modelo físico em escala real, simulando o chute e sua estrutura de suporte, utilizado por Beus et alii (1997).

HAMBLEY, D. F. Design of ore pass systems for underground mines. CIM Bulletin, 80, p. 25-30, 1987.

HARTMAN, H. L. Introductory Mining Engineering. John Wiley, 1987.

JANELID, I., KVAPIL, R. Sublevel Caving. International Journal of Rock Mechanics and Mining Sciences \& Geomechanics Abstracts, v.3, p. 129153, 1966.

KVAPIL, R. Gravity flow of granular materials in hoppers and bins in mines part II: coarse materials. International Journal of Rock Mechanics and Mining Sciences \& Geomechanics Abstracts, v. 2, p. 277-304, 1965.
PFLEIDER, E. P., SELLECK, D.J. Ore passes, tunnels and shafts. Surface Mining. AIME. New York, p. 637-648, 1968.

STACEY, T. R., SWART, A. H. Investigation into draw points, tips, ore passes and chutes. Safety in mines research advisory committee, v. 1, 1997. 105 p.

Artigo recebido em 25/10/2005 e aprovado em 19/05/2006.

www.rem.com.br 